\title{
Different molecular conformation and packing determining mechanochromism and room- temperature phosphorescence
}

\author{
Shuhui $\mathrm{Li}^{1,2}$, Yujun $\mathrm{Xie}^{2}$, Aisen $\mathrm{Li}^{2}$, Xiaoning $\mathrm{Li}^{2}$, Weilong $\mathrm{Che}^{2}$, Jinfeng Wang ${ }^{2^{*}}$, Heping Shi ${ }^{{ }^{*}}$ and \\ Zhen $\mathrm{Li}^{2,3,4^{*}}$
}

\begin{abstract}
The phenomenon that different molecular packing modes in aggregates result in different optical properties has attracted intense attention, since it can provide useful information to establish the relationship between the micro- and macro-world. In this paper, DBTDO-DMAC was designed with 9,10-dihydro-9,9-dimethylacridine (DMAC) as electron donor. DBTDO-DPA and DBTDO-Cz were designed for comparison, which adopted diphenylamine (DPA) with twisted structure and carbazole $(\mathrm{Cz})$ with planar structure as donors, respectively. As expected, two polymorphs (Crystal G and Crystal Y) of DBTDO-DMAC were obtained and exhibited distinct properties. Crystal $G$ originating from planar conformation exhibited mechanochromism (MC) phenomenon and the emission color changed from green to yellow with a redshift of $35 \mathrm{~nm}$ after grinding. Nevertheless, Crystal Y with folded conformation displayed obvious room-temperature phosphorescence (RTP) with yellow afterglow. Careful single crystal analyses, powder $\mathrm{X}$-ray diffraction and theoretical calculation reveal that the different emissive behaviors are highly related to the molecular conformation and packing modes. The successful adjustment of molecular conformation provides some guidance in the design of other MC and/or RTP luminogens, broadens the molecule family with the tunable molecular conformation and opens up a new avenue for exploring possible adjustment of molecular packing in aggregates.
\end{abstract}

Keywords: molecular packing, conformation, mechanochromism, room temperature phosphorescence

\section{INTRODUCTION}

Purely organic luminescent materials have been widely investigated due to their potential applications in optoelectronic devices, biological imaging and information encryption [1-20]. Although the emissive behaviors are closely related to the electronic nature of the molecular structure, the molecular packing mode also affects the property to a large extent. Recently, the concept of "Molecular Uniting Set Identified Characteristic (MUSIC)" has been put forward by Li et al. [21], which clearly elucidates the importance of packing mode for different emission types, including room-temperature phosphorescence (RTP), mechanochromism (MC), and mechanoluminescence (ML) [22-25]. As typical examples, polymorphs with different molecular packing and completely different properties emphasize the critical roles of molecular packing [26-30]. For instance, three polymorphs of anthracene derivative (BP2VA, Fig. S1a) exhibit different fluorescence, mainly due to their different $\pi-\pi$ stacking modes [28]. Additionally, the totally different RTP emission colours and lifetimes of phenothiazine derivative (CzS-CN, Fig. S1b) could be found in three different molecular arrangements of polymorphisms [29]. Moreover, triphenylamine derivate (TPA-o-3COOMe, Fig. S1c) displays two different packing modes with totally different ML and RTP properties, showing the key role of molecular packing [30].

As well-known, different molecular conformations could result in different molecular packing modes, and then further influence their corresponding properties

\footnotetext{
${ }^{1}$ School of Chemistry and Chemical Engineering, Shanxi University, Taiyuan 030006, China

${ }^{2}$ Institute of Molecular Aggregation Science, Tianjin University, Tianjin 300072, China

${ }^{3}$ Department of Chemistry, Wuhan University, Wuhan 430072, China

${ }^{4}$ Joint School of National University of Singapore and Tianjin University, International Campus of Tianjin University, Fuzhou 350207, China

* Corresponding authors (emails: jinfeng.wang@tju.edu.cn (Wang J); hepingshi@sxu.edu.cn (Shi H); lizhentju@tju.edu.cn, or lizhen@whu.edu.cn (Li Z))
} 
[29,31-38]. Phenothiazine derivatives with quasi-axial (ax) and quasi-equatorial (eq) conformations show distinct features due to the different electronic configurations caused by the existence of $d$ orbitals from sulfur atom $[39,40]$. The diverse stacking modes based on the different conformations of phenothiazine and the resulting various properties have been extensively studied, offering the design of phenothiazine derivatives more flexibility with tunable functionality [41-48]. However, the successful adjustment of molecular conformation is still very scarce. Thus, to broaden the molecule family with tunable molecular conformation, new constructing blocks should be further explored.

9,10-Dihydro-9,9-dimethylacridine (DMAC) derivatives primarily exhibit the folded conformation and a few cases with planar conformation [49-52]. These two different conformations of DMAC derivatives inspire the great potential to form different packing modes and intriguing properties with the same chemical structure through reasonable molecular design, which should be helpful to explore the relationship of molecular structurepacking-property. Accordingly, in this study, taking DMAC with the potential to form two different conformations as the electron donor, a donor-acceptor (D-A) structure of DBTDO-DMAC was constructed by incorporating dibenzothiophene 5,5-dioxide (DBTDO) with two oxygen atoms as electron acceptor, which may supply much more intermolecular hydrogen bonds and enhance intermolecular interactions, so as to inhibit the non-radiative transition. For comparison, two analogues were synthesized, that were, 2-(cyclohexa-2,4-dien-1-yl (phenyl)amino) dibenzo[b,d]thiophene 5,5-dioxide (DBTDO-DPA) and 2-(4a,9a-dihydro-9H-carbazol-9-yl) dibenzo[b,d]thiophene 5,5-dioxide (DBTDO-Cz) adopting diphenylamine and carbazole $(\mathrm{Cz})$ as electron donors, respectively. The $\mathrm{Cz}$ and diphenylamine are $\mathrm{N}$-containing heterocyclic donors and the sizes of the functional groups are similar to acridine [53]. More importantly, DMAC exhibits folded or planar conformations as reported in literatures [49-52], the twisted conformation of diphenylamine is similar to the folded conformation of DMAC and the planar conformation of $\mathrm{Cz}$ is similar to the planar conformation of DMAC group [54-57], which would help to deeply understand the effect of stacking on the performance through structural comparison. As expected, two polymorphs (Crystal G and Crystal Y) of DBTDODMAC were successfully obtained, with different conformations and packing. Crystal $G$ originating from planar conformation exhibited obvious MC, while Crystal Y with the folded conformation exhibited visible RTP.
Through careful analysis of crystal structures, the preferred packing modes of these two emission forms were found, which was conduciveing to further uncovering the molecular structure-packing-property relationship (Fig. 1).

\section{EXPERIMENTAL SECTION}

\section{Materials}

2-Bromodibenzothiophene (2-BrDBT), acetic acid, hydrogen peroxide, $9 \mathrm{H}-\mathrm{Cz}$, diphenylamine (DPA), DMAC, potassium tert-butanolate, palladium(II) acetate, tri-tertbutylphosphine tetrafluoroborate were commercial source and directly used without further purification. Toluene was chromatographically pure taken from the anhydrous and anaerobic system of vigor company.

\section{Characterization}

${ }^{1} \mathrm{H}$ nuclear magnetic resonance (NMR) and ${ }^{13} \mathrm{C} \mathrm{NMR}$ spectra were measured by Bruker AVANCE $400 \mathrm{MHz}$ spectrometer or JNM-ECZ600R/S1 $\left(\mathrm{CDCl}_{3}\right.$, tetramethylsilane as the internal standard). The high-resolution mass spectra (HRMS) were measured by Bruker Daltonics ESI-micrOTOF Q II. Single-crystal X-ray diffraction (XRD) data of these samples were collected at room temperature on a SuperNova, Dual, $\mathrm{Cu}$ at zero, Atlas diffractometer equipped with graphite-monochromated $\mathrm{Cu} \mathrm{Ka}$ radiation $(\lambda=1.54184 \AA)$. Powder XRD (PXRD) patterns of these samples were performed on a Rigaku MiniFlex II with $\mathrm{Cu} \mathrm{Ka}$ radiation $(\lambda=$ $1.5406 \AA$ ), and the measurements were made in the range of $3^{\circ}-60^{\circ}$ at room temperature with a step of $0.01^{\circ}(2 \theta)$ as well as a scan speed of $10^{\circ} \mathrm{min}^{-1}$. The operating power was $40 \mathrm{kV}, 30 \mathrm{~mA}$. UV-vis absorption spectra were obtained on a Shimadzu UV-2600 spectrophotometer at room temperature. The photoluminescence (PL) spectra were measured by Hitachi F-4700 for solution and Edinburgh Analytical instrument FLS 1000 for solid. The phosphorescence spectra, time-resolved PL-decay curves and quantum yields were measured on Edinburgh Analytical instrument FLS 1000 equipped with both xenon arc lamp (450 W) and pulsed flash lamps.

\section{Syntheses}

\section{Synthesis of 2-BrDBTDO}

2-BrDBT ( $1 \mathrm{~g})$ was added into $\mathrm{AcOH}(24 \mathrm{~mL})$ and stirred for half an hour. Then, $30 \% \mathrm{H}_{2} \mathrm{O}_{2}(36 \mathrm{~mL})$ was added to the mixture dropwise at room temperature. After refluxing for $10 \mathrm{~h}$, the mixture was cooled to room tem- 


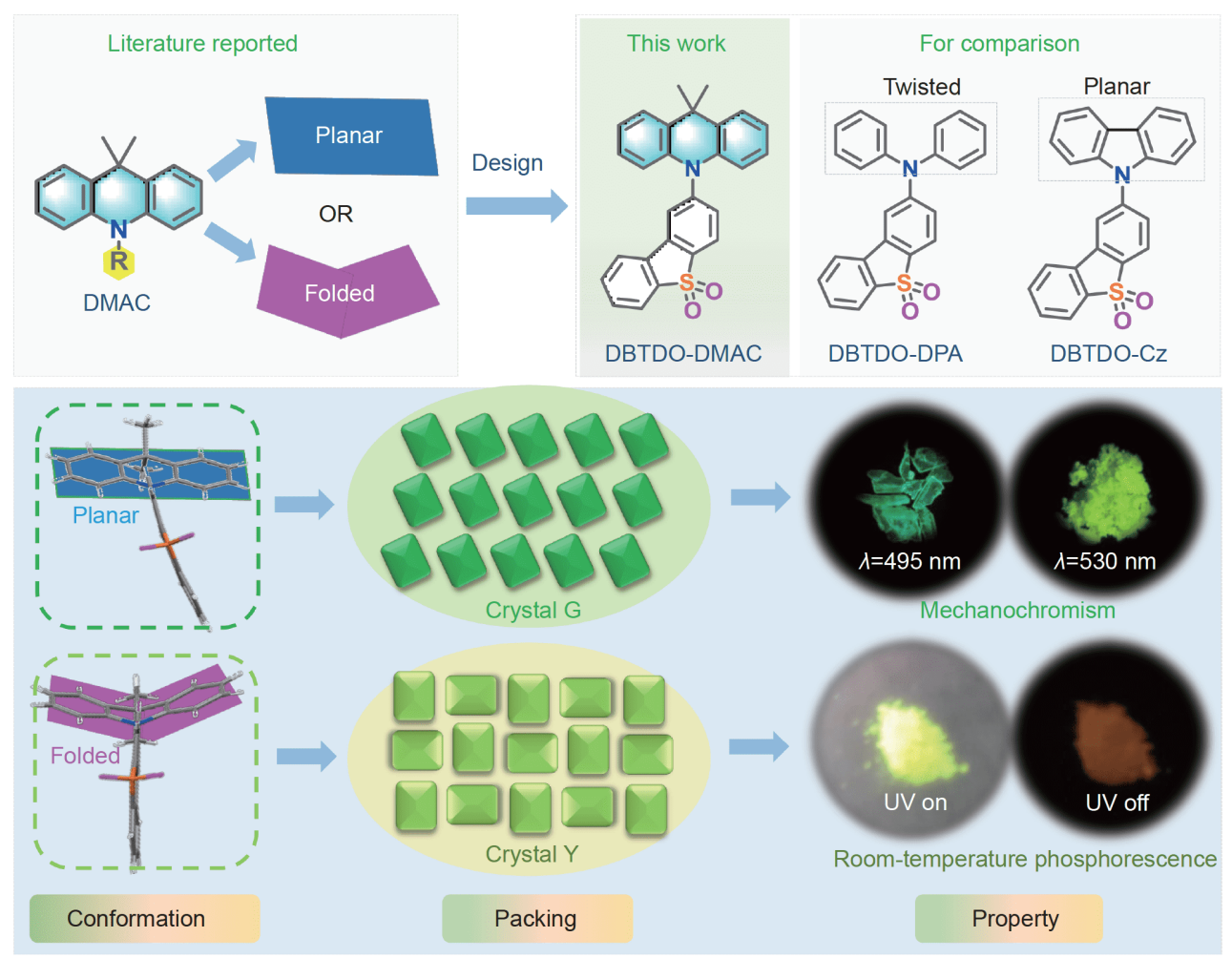

Figure 1 The design idea, molecular structures and the different emission forms of DBTDO-DMAC in polymorphs.

perature and filtrated. The white solid was washed with water until the $\mathrm{pH}$ was neutral and dried with vacuum oven to give a white solid (1.098 g, yield: $98 \%) .{ }^{1} \mathrm{H}$ NMR $(400 \mathrm{MHz}$, chloroform-d) $\delta=7.95(\mathrm{~s}, 1 \mathrm{H}), 7.84(\mathrm{~d}, J=$ $7.5 \mathrm{~Hz}, 1 \mathrm{H}), 7.78(\mathrm{~d}, J=7.6 \mathrm{~Hz}, 1 \mathrm{H}), 7.68(\mathrm{~d}, J=5.4 \mathrm{~Hz}$, $3 \mathrm{H}), 7.59(\mathrm{~d}, J=7.6 \mathrm{~Hz}, 1 \mathrm{H})$.

\section{Synthesis of DBTDO-DMAC}

A mixture of 2-BrDBTDO (200 mg, $0.68 \mathrm{mmol}$ ), DMAC $(0.213 \mathrm{~g}, 1 \mathrm{mmol})$, potassium tert-butanolate $(191 \mathrm{mg}$, $1.7 \mathrm{mmol}$ ), palladium(II) acetate $(15 \mathrm{mg}, 10 \%)$ and tritert-butylphosphine tetrafluoroborate $(30 \mathrm{mg}, 15 \%)$ in toluene $(15 \mathrm{~mL})$ was refluxed under argon for $32 \mathrm{~h}$. Then, the mixture was filtrated and further purified through silica-gel column chromatography with petroleum ether $(\mathrm{PE}) / \mathrm{EtOAc}(15 / 1, v / v)$ as eluent to give a yellow solid (192 mg, yield: 66\%). ${ }^{1} \mathrm{H}$ NMR (600 MHz, chloroform-d) $\delta=8.13-8.07(\mathrm{~m}, 1 \mathrm{H}), 7.90(\mathrm{~d}, J=7.7 \mathrm{~Hz}, 1 \mathrm{H}), 7.79(\mathrm{~d}$, $J=1.6 \mathrm{~Hz}, 1 \mathrm{H}), 7.73(\mathrm{~d}, J=7.5 \mathrm{~Hz}, 1 \mathrm{H}), 7.66(\mathrm{t}, J=$ $7.5 \mathrm{~Hz}, 1 \mathrm{H}), 7.59$ (t, $J=7.5 \mathrm{~Hz}, 1 \mathrm{H}), 7.54(\mathrm{~d}, J=8.0 \mathrm{~Hz}$, $1 \mathrm{H}), 7.51(\mathrm{~d}, J=7.4 \mathrm{~Hz}, 2 \mathrm{H}), 7.01(\mathrm{~m}, J=7.4 \mathrm{~Hz}, 4 \mathrm{H})$, $6.32(\mathrm{~d}, J=8.9 \mathrm{~Hz}, 2 \mathrm{H}), 1.71(\mathrm{~s}, 6 \mathrm{H}) .{ }^{13} \mathrm{C} \mathrm{NMR}(100 \mathrm{MHz}$, chloroform-d) $\delta=147.36,140.18,138.16,136.89,135.19$,
$134.23,133.26,131.10,130.89,126.76,125.80,124.94$, $124.48,122.55,122.13,121.67,114.45,36.22,31.48$. Electrospray ionization tandem (ESI)-HRMS: $\mathrm{m} / z$ calcd. for $\mathrm{C}_{27} \mathrm{H}_{21} \mathrm{NNaO}_{2} \mathrm{~S},[\mathrm{M}+\mathrm{Na}]^{+}$, 446.1185; found, 446.1175.

\section{Synthesis of DBTDO-DPA}

A mixture of 2-BrDBTDO (200 mg, $0.68 \mathrm{mmol}$ ), DPA $(137 \mathrm{mg}, 0.8 \mathrm{mmol})$, potassium tert-butanolate $(191 \mathrm{mg}$, $1.7 \mathrm{mmol})$, palladium(II) acetate $(8 \mathrm{mg}, 5 \%)$ and tri-tertbutylphosphine tetrafluoroborate $(15 \mathrm{mg}, 7.5 \%)$ in toluene $(10 \mathrm{~mL})$ was refluxed under argon atmosphere for $18 \mathrm{~h}$. Then, the mixture was filtrated and further purified by silica-gel column chromatography with PE:EtOAc (20/ $1, v / v)$ as eluent to give a yellow solid (164 $\mathrm{mg}, 63 \%$ yield). ${ }^{1} \mathrm{H}$ NMR $(400 \mathrm{MHz}$, chloroform-d) $\delta=7.80$ (d, $J=$ $7.4 \mathrm{~Hz}, 1 \mathrm{H}), 7.60(\mathrm{~d}, J=8.5 \mathrm{~Hz}, 1 \mathrm{H}), 7.54(\mathrm{~d}, J=3.9 \mathrm{~Hz}$, $2 \mathrm{H}), 7.49(\mathrm{dt}, J=8.6 \mathrm{~Hz}, 4.3,1 \mathrm{H}), 7.44-7.32(\mathrm{~m}, 4 \mathrm{H}), 7.31$ $(\mathrm{d}, J=2.0 \mathrm{~Hz}, 1 \mathrm{H}), 7.24-7.08(\mathrm{~m}, 6 \mathrm{H}), 7.03(\mathrm{dd}, J=$ $8.5 \mathrm{~Hz}, 2.1 \mathrm{~Hz}, 1 \mathrm{H}) .{ }^{13} \mathrm{C}$ NMR $(150 \mathrm{MHz}$, chloroform-d) $\delta=153.36,146.31,138.80,133.56,133.47,131.63,130.40$, $129.99,128.69,126.11,125.22,123.33,122.05,121.77$, 121.62, 112.49. ESI-HRMS: $\mathrm{m} / z$ calcd. for $\mathrm{C}_{24} \mathrm{H}_{18} \mathrm{NO}_{2} \mathrm{~S}$, $[\mathrm{M}+\mathrm{H}]^{+}$, 384.1053; found, 384.1048. 


\section{Synthesis of $\mathrm{DBTDO}-\mathrm{Cz}$}

A mixture of 2-BrDBTDO (200 mg, $0.68 \mathrm{mmol}$ ), commercial $\mathrm{Cz}(138 \mathrm{mg}, 0.8 \mathrm{mmol})$, potassium tert-butanolate (191 mg, $1.7 \mathrm{mmol})$, palladium(II) acetate ( $8 \mathrm{mg}, 5 \%)$ and tri-tert-butylphosphine tetrafluoroborate $(15 \mathrm{mg}$, $7.5 \%)$ in toluene $(15 \mathrm{~mL})$ was refluxed under argon for 20 $\mathrm{h}$. Then, the mixture was filtrated and further purified through gradient elution of column chromatography to give a white solid (62 mg, $24 \%$ yield). ${ }^{1} \mathrm{H}$ NMR $(600 \mathrm{MHz}$, chloroform-d) $\delta=8.17(\mathrm{~d}, J=7.7 \mathrm{~Hz}, 2 \mathrm{H}), 8.08(\mathrm{~d}, J=$ $8.0 \mathrm{~Hz}, 1 \mathrm{H}), 8.02(\mathrm{~s}, 1 \mathrm{H}), 7.91(\mathrm{~d}, J=7.7 \mathrm{~Hz}, 1 \mathrm{H}), 7.79$ $(\mathrm{dd}, J=15.2 \mathrm{~Hz}, 7.9 \mathrm{~Hz}, 2 \mathrm{H}), 7.68(\mathrm{t}, J=7.5 \mathrm{~Hz}, 1 \mathrm{H}), 7.61$ $(\mathrm{t}, J=7.6 \mathrm{~Hz}, 1 \mathrm{H}), 7.47(\mathrm{~d}, J=5.9 \mathrm{~Hz}, 4 \mathrm{H}), 7.36(\mathrm{t}, J=$ $6.9 \mathrm{~Hz}, 2 \mathrm{H}) .{ }^{13} \mathrm{C}$ NMR $(150 \mathrm{MHz}$, chloroform-d) $\delta=$ $143.48,140.24,138.38,135.84,134.23,134.18,131.22$, $130.91,128.57,126.61,124.13,124.08,122.57,122.02$, $121.13,120.78,119.88,109.68$. ESI-HRMS: $\mathrm{m} / z$ calcd. for $\mathrm{C}_{24} \mathrm{H}_{16} \mathrm{NO}_{2} \mathrm{~S},[\mathrm{M}+\mathrm{H}]^{+}, 382.0896$; found, 382.0897 .

\section{RESULTS AND DISCUSSION}

All of the target compounds were synthesized via Buch-
wald-Hartwig cross coupling (Scheme 1) and characterized by ${ }^{1} \mathrm{H}$ NMR, ${ }^{13} \mathrm{C}$ NMR, and HRMS (Figs S2-S11). The UV-vis absorption and PL spectra of these three compounds were measured in tetrahydrofuran (THF) (Fig. 2). These compounds exhibit two partly similar absorption bands: the intense absorption at shorter wavelengths $(\leq 300 \mathrm{~nm})$ could be ascribed to the $\pi-\pi^{*}$ transitions, while the broad and weak absorption bands at longer wavelengths could be assigned to the intramolecular charge transfer (ICT) transitions from the donor units to the acceptor. The absorption band shifts to longer wavelength with the increase of electron-donating ability in the order of DMAC, $\mathrm{Cz}$ and DPA, which is in good accordance with the calculated results (Fig. S12). Meanwhile, DBTDO-DMAC, DBTDO-DPA and DBTDO-Cz in dilute THF solutions exhibit emission bands $\left(\lambda_{\max }\right)$ at 530,474 and $438 \mathrm{~nm}$, respectively. The much more red-shift emission of DBTDO-DMAC may be attributed to the quasi anthracene skeletons of DMAC [58]. Their photophysical properties are shown in Fig. 2 and Fig. S13, and summarized in Table S1. Besides, all of

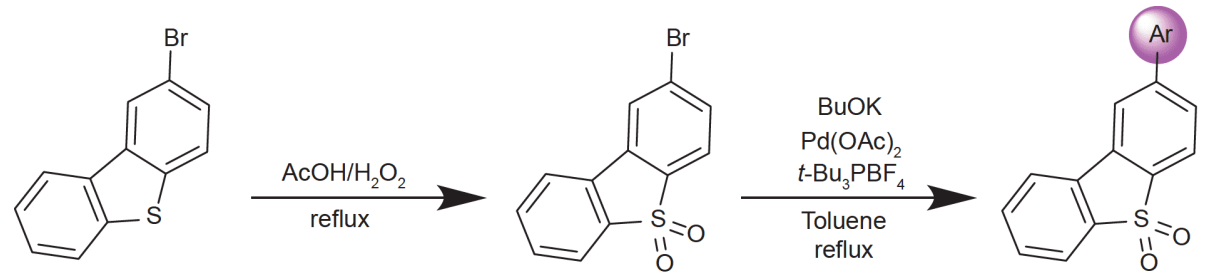

2-BrDBT

2-BrDBTDO
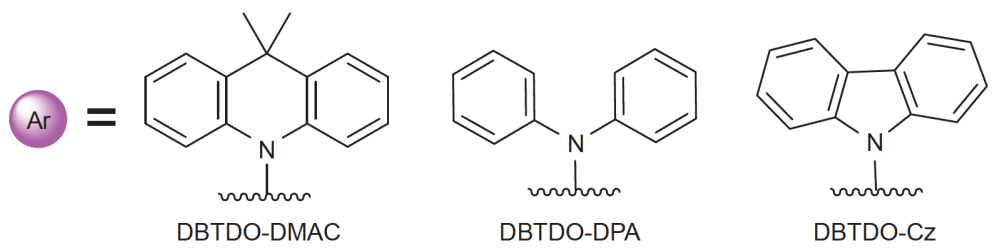

Scheme 1 Synthetic routes of DBTDO-DMAC, DBTDO-DPA and DBTDO-Cz.
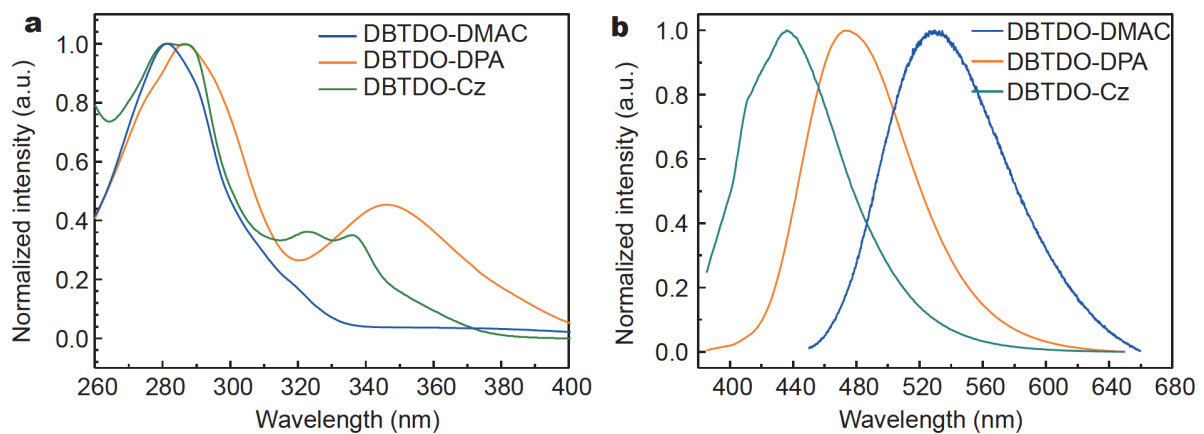

Figure 2 (a) Absorption and (b) PL spectra of DBTDO-DMAC, DBTDO-DPA and DBTDO-Cz in THF $\left(5 \times 10^{-5} \mathrm{~mol} \mathrm{~L}^{-1}\right)$. 
the three compounds demonstrate typical bathochromicshifts with the increasing solvent polarity (Fig. S14), further manifesting the ICT transitions in these molecules.

Furthermore, two polymorphs of DBTDO-DMAC were obtained by controlling the volatilization rate of the mixture solution (dichloromethane $/ n$-hexane $=1 / 1$ ). The lamellar crystal (Crystal G, CCDC 2050270) with green emission $\left(\lambda_{\max }=495 \mathrm{~nm}, \Phi=8.95 \%\right)$ exhibits obvious MC behavior (Fig. 3a). When Crystal G was ground using a pestle and a mortar at room temperature, the amorphous powder was yielded and turned to yellow emission $\left(\lambda_{\max }=530 \mathrm{~nm}\right)$ with the enhanced emission intensity, as confirmed by the increased quantum yield $(\Phi=18.43 \%)$. That is to say, the largest emission wavelength of crystal G displays an obvious bathochromic shift from 495 to $530 \mathrm{~nm}$ after grinding with the color changing from green to yellow. Nevertheless, the cuboid crystal (Crystal Y, CCDC 2050271) exhibits yellow emission $\left(\lambda_{\max }=533 \mathrm{~nm}\right.$, $\Phi=13.77 \%$ ). After grinding, the maximum emission peak changes to $530 \mathrm{~nm}$. The change of the maximum emission wavelength before and after grinding is negligible for Crystal Y. Interestingly, Crystal Y displays obvious yellow RTP at $538 \mathrm{~nm}$ with the lifetime of $3.17 \mathrm{~ms}$ (Fig. 3b), but no visible RTP could be observed by naked eyes for Crystal G at $518 \mathrm{~nm}(\tau=12.99 \mu \mathrm{s})$. Their totally different properties including wavelength, lifetime and quantum yield are highly dependent on the different molecular packing in aggregates (Fig. 3c and Fig. S15). However, the MC behavior and RTP are hardly observed for DBTDODPA (CCDC 2050274) and DBTDO-Cz (CCDC 2050273) with the lifetime of only several nanoseconds. The maximum emission wavelength of DBTDO-DPA $\left(\lambda_{\max }=460 \mathrm{~nm}\right)$ and DBTDO-Cz $\left(\lambda_{\max }=435 \mathrm{~nm}\right)$ changed to 472 and $433 \mathrm{~nm}$, respectively, after grinding. The difference of the maximum emission wavelength before and after grinding can be almost ignored, and the emission color has no obvious change (Fig. S16, Table S2), further indicating that the molecular conformation and packing significantly affect the properties.

To gain deeper insight into the intrinsic mechanism of these different properties of DBTDO-DMAC, singlecrystal XRD was conducted. As depicted in Fig. 4, the molecular conformations for DBTDO-DMAC in the two polymorphs are totally different from each other. The conformation of DMAC in Crystal G exhibits almost a planar conformation with a small dihedral angle $\left(2.84^{\circ}\right)$ and the two molecules in the dimer show a reverse staggered arrangement with no overlap. The four types of $\mathrm{C}-\mathrm{H}$...O ranging from 2.822 to $3.926 \AA$ occur alone, demonstrating a slightly weaker intramolecular interactions and some labile factors under the external stimuli, which is prone to MC for Crystal G. However, Crystal Y exhibits a folded conformation with a dihedral angle of
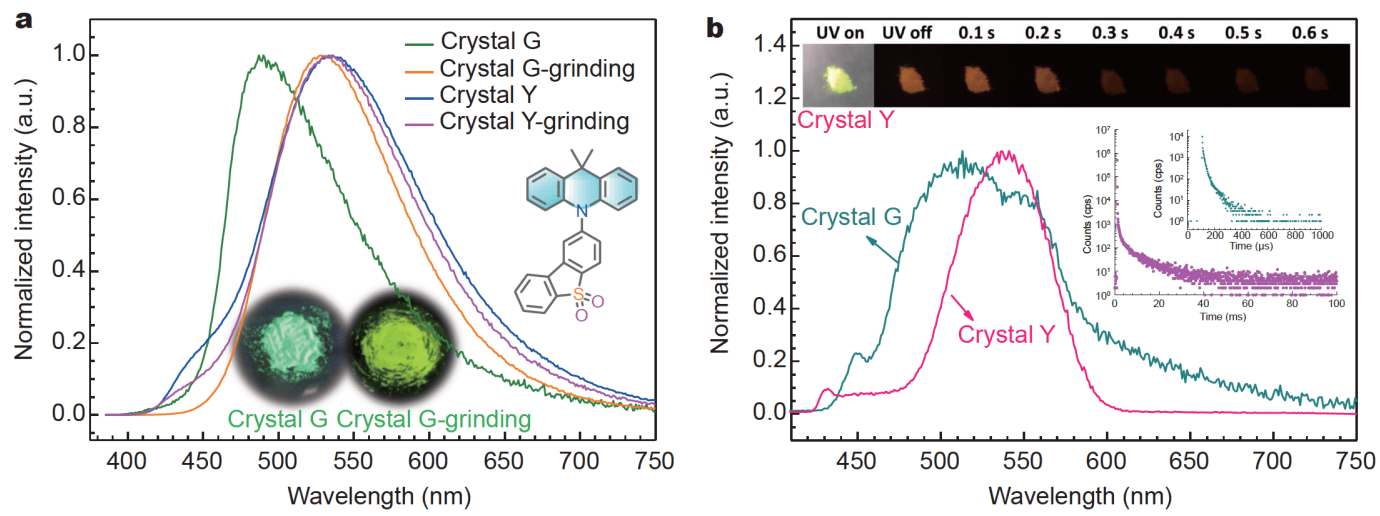

\begin{tabular}{|c|c|c|c|c|c|c|}
\hline \multirow{2}{*}{ DBTDO-DMAC } & \multirow{2}{*}{ Space group } & \multicolumn{3}{|c|}{ Fluorescence } & \multicolumn{2}{|c|}{ Phosphorescence } \\
\hline & & $\lambda(\mathrm{nm})$ & $\tau(\mathrm{ns})$ & $\varphi(\%)$ & $\lambda(\mathrm{nm})$ & $\tau(\mu \mathrm{s})$ \\
\hline Crystal G & Cc & 495 & 10.99 & 8.95 & 518 & 12.99 \\
\hline Crystal Y & $P 2_{1} / n$ & 533 & 22.96 & 13.77 & 538 & 3170 \\
\hline Amorphous & - & 530 & 23.21 & 18.43 & 518 & 8.98 \\
\hline
\end{tabular}

Figure 3 (a) PL spectra of DBTDO-DMAC in Crystals G and Y before and after grinding; Inset: the corresponding images of Crystal G. (b) Phosphorescence spectra and time-resolved phosphorescence-decay curves of DBTDO-DMAC in Crystals G and Y; Inset: images of Crystal Y before and after the removal of UV excitation source at ambient conditions. (c) Photophysical properties of DBTDO-DMAC. 


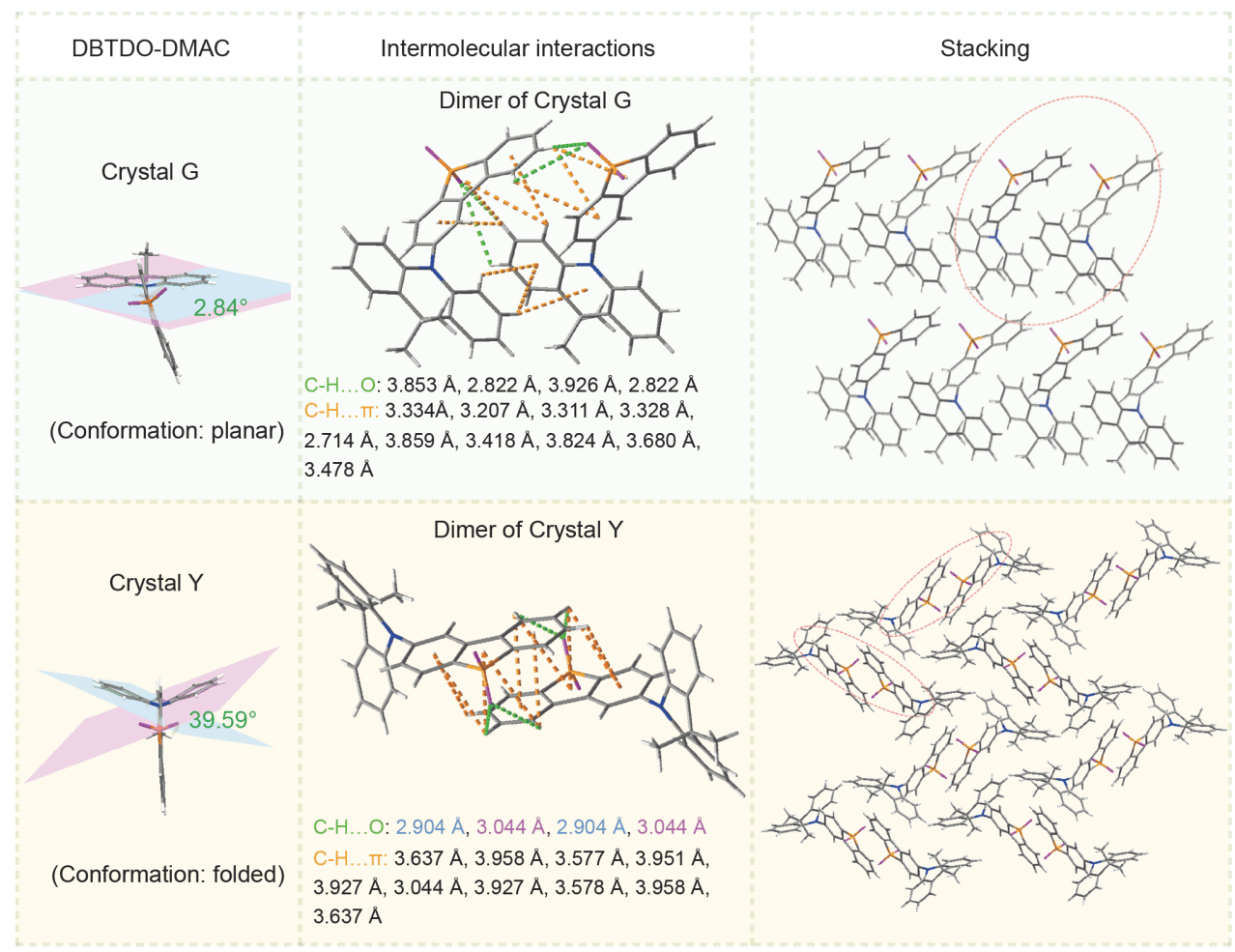

Figure 4 The conformations, intermolecular interactions, and stacking modes of DBTDO-DMAC in polymorphs.

$39.6^{\circ}$. As shown in Fig. 4, the two molecules in the dimer display a stronger $\pi-\pi$ interaction in Crystal $Y$ with a faceto-face antiparallel arrangement, the distance of $3.816 \AA$ and overlap of $45.3 \%$ (Fig. S17). The strong $\pi-\pi$ interactions in solid state could promote the persistent RTP $[59,60]$. In addition, there are four types of C-H...O and ten types of $\mathrm{C}-\mathrm{H} \ldots \pi$ intramolecular interactions in the dimer of Crystal Y. It is worth noting that the intramolecular interactions in the dimer occur in pairs, which will restrict the intermolecular motions effectively and reduce the non-radiative transition, contributing much to the longer RTP lifetime $(3.17 \mathrm{~ms})$ as well as its higher PL quantum efficiency (13.77\%) than Crystal G. Meanwhile, the red-shift fluorescence and non-mechanochromism of Crystal $\mathrm{Y}$ are also ascribed to the packing mode and symmetrical intermolecular interactions. Furthermore, the interactions between dimers of Crystal G and Crystal Y were analyzed (Fig. S18). Two types of C$\mathrm{H}$...O intermolecular interactions and four types of $\mathrm{C}-$ $\mathrm{H} . . . \pi$ intermolecular interactions existed between the dimers. As previously mentioned, the interactions in Crystal Y were stronger than that in Crystal G, confirming the effective inhibition of molecular motions and the reduction of the non-radiative transitions, which contributed much to the longer RTP.

For DBTDO-DPA and DBTDO-Cz, the two molecules in each dimer display a face-to-face antiparallel arrangement similar to Crystal Y of DBTDO-DMAC (Fig. S19). However, the $\pi-\pi$ distance of DBTDO-DPA and DBTDO-Cz are 4.806 and $4.710 \AA$, which are much longer than the $\pi-\pi$ distance of Crystal Y. Moreover, DBTDO-DPA and DBTDO-Cz also exhibit weaker and less $\mathrm{C}-\mathrm{H} . . . \mathrm{O}$ and $\mathrm{C}-\mathrm{H} \ldots \pi$ interactions, which are insufficient to suppress the non-radiative transitions for the realization of RTP.

In order to investigate the influence of the molecular conformations on their RTP effect, time-dependent density functional theory ( TD-DFT) calculations on the energy level and related excited state transition for singlet $(\mathrm{S})$ and triplet $(\mathrm{T})$ states were conducted, based on the monomers and dimers (Fig. 5). The effective intersystem crossing (ISC) channels are related to the small energy gap $(\leq 0.3 \mathrm{eV})$ and the same transition orbital compositions as the $S_{1}$ state. For Crystal $G$, the monomers show two effective transition channels from $S_{1}$ to $T_{1}$ and $S_{1}$ to $\mathrm{T}_{2}$ states, while the dimer exhibits only one effective transition channel from $S_{1}$ to $T_{1}$ states. The monomers of Crystal $\mathrm{Y}$ also display two effective transition channels, 

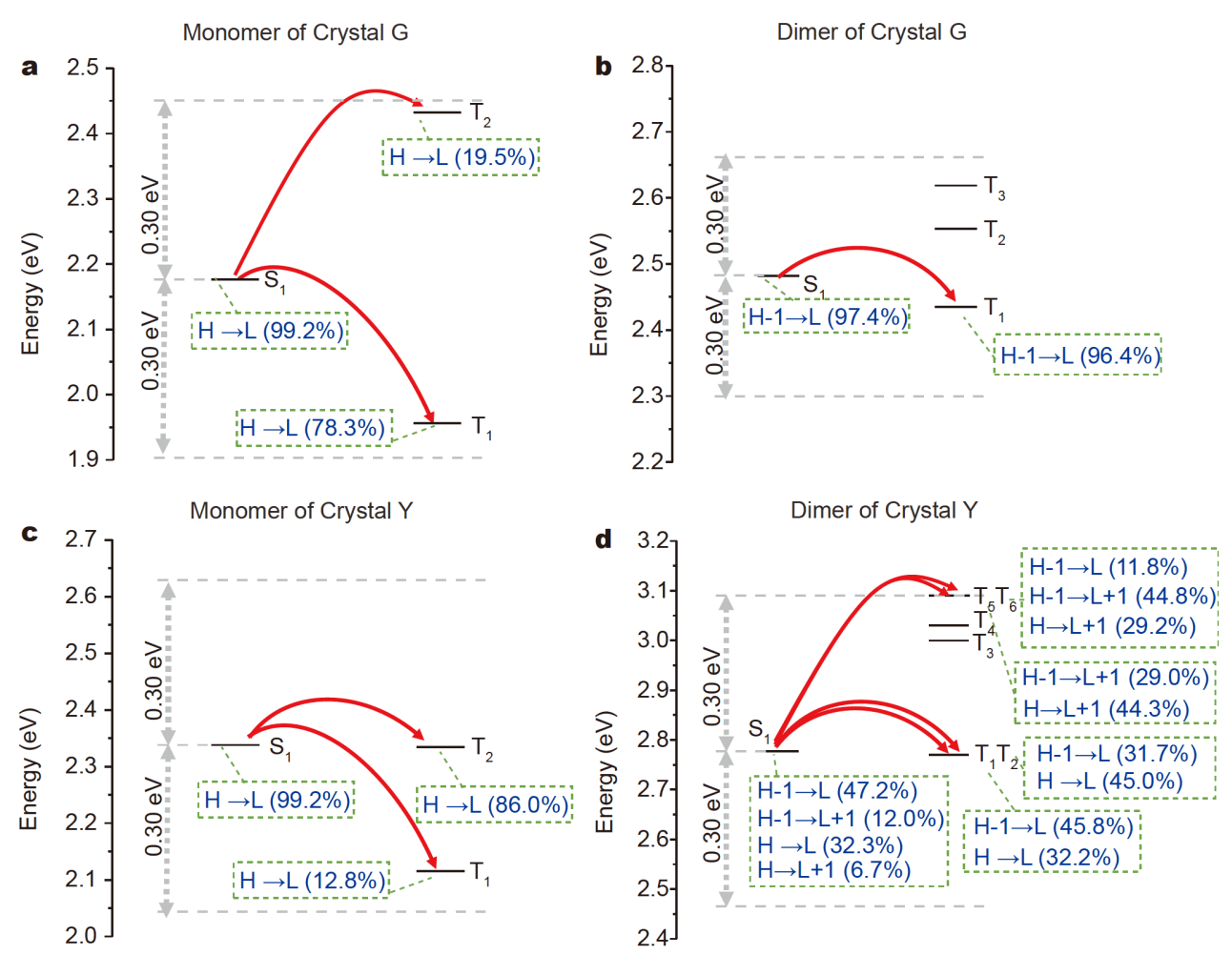

Figure 5 Theoretical calculations for monomer of (a) Crystal G, (c) Crystal Y and dimer of (b) Crystal G, (d) Crystal Y of DBTDO-DMAC.

demonstrating the similarity of monomers of Crystal G and Crystal Y. However, there are four effective transition channels from $S_{1}$ to $T_{n}$ for the dimer of Crystal $Y$, owing to the big changes of the molecular packing. Combined with the strong intermolecular interactions in Crystal Y with antiparallel arrangement, its persistent RTP is mainly due to the facilitated ISC process to generate the excited triplet state and restrict the non-radiative transitions through the multiple symmetrical intermolecular noncovalent interactions to stabilize the triplet excitons [61-63]. In contrast, the ISC channels of the monomers in DBTDO-DPA and DBTDO-Cz occur only from $S_{1}$ to $\mathrm{T}_{1}$ (Fig. S20). There are two effective ISC channels for the dimer of DBTDO-DPA and three ISC channels for the dimer of DBTDO-Cz, which are less than Crystal Y of DBTDO-DMAC. Additionally, the relatively low proportion of the similar components between $\mathrm{T}_{n}$ state and $\mathrm{S}_{1}$ state was observed, indicating the weak ISC process in the dimers of DBTDO-DPA and DBTDO-Cz. Thus, the weak ISC process, along with the weak intermolecular interactions and few $\pi-\pi$ interactions may prevent the realization of RTP.

The powder XRD was further performed to investigate the distinct MC behavior in response to external stimuli, such as grinding and solvent exposure (Fig. 6a). The XRD patterns of Crystals $G$ and $Y$ exhibit sharp and strong diffraction peaks with significant difference. Crystal G shows main signal peaks at $12^{\circ}$ and $22^{\circ}$, while Crystal $\mathrm{Y}$ displays the main signal peaks located at $15^{\circ}$ and $23^{\circ}$, which is indicative of their highly ordered crystalline nature and different stacking modes. After grinding, the sharp peaks weaken by a large margin and even vanish, suggesting the transformation from crystalline to amorphous nature, which results in the red-shifted PL spectra of Crystal G from green to yellow. It should be noted that the ground sample was transferred to Crystal $\mathrm{Y}$ rather than the initial Crystal $G$ by fuming with dichloromethane (DCM) vapour for $90 \mathrm{~min}$ (Fig. S21), because of the much stronger intermolecular interactions and the enhanced stability of Crystal $\mathrm{Y}$ rather than Crystal G [64].

Given that the MC was only observed apparently in Crystal $G$ with obvious changes from green to yellow emission simply pressed by a metal spatula, the microcrystalline $G$ was spread on the surface of plexiglass as a green background (Fig. 6b). By using the spoon to write on the surface of plexiglass, the letter "Music 505" appeared at the written area under $365 \mathrm{~nm}$ UV light and 

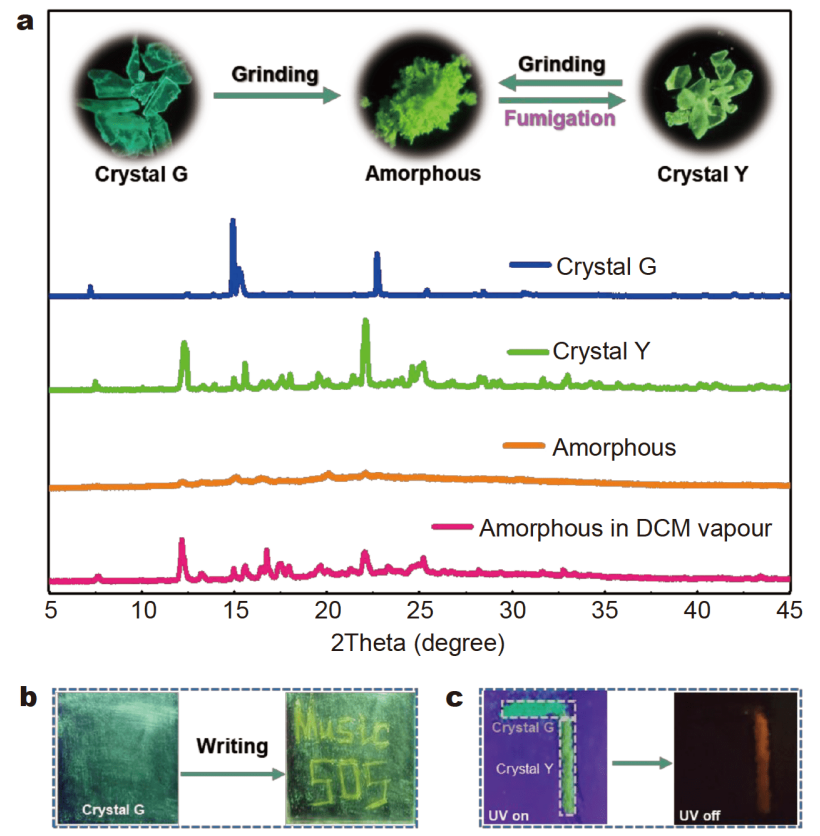

Figure 6 (a) Images and PXRD of DBTDO-DMAC in polymorphs and amorphous phase before and after fuming in DCM vapor. (b) Writing "Music 505" with a spoon with microcrystal G. (c) The Images of the pattern of " 7 " and " 1 " with Crystal G and Crystal Y before and after switching off the $365 \mathrm{~nm}$ lamp.

was clearly recorded, suggesting the potential applications for optical recording. In contrast, Crystal Y with RTP was applied to anti-counterfeiting. As shown in Fig. 6c, "-”" and "|" were prepared using Crystals G and Y, respectively, which were combined to arrange as a number "7". Under UV-excitation, a digital " 7 " with the green-yellow emission was clearly observed. Fascinatingly, when the UV lamp excitation was ceased, the digital changed to yellow "1", which confirmed the potential applications in anti-counterfeiting and information encryption.

\section{CONCLUSIONS}

In summary, DBTDO-DMAC with two polymorphs were designed and synthesized. More importantly, the polymorphs with two different molecular conformations show MC and RTP, respectively. Single crystal analysis and theoretical calculations demonstrate the key role of molecular conformation and packing mode on their photophysical properties, which could provide some guidance in the design of other MC and/or RTP luminogens. In addition, besides the electron properties and the spatial configuration, molecular conformation should also be considered seriously for the adjustment of molecular aggregates. Considering the molecular structure, the change of molecular conformation opens up a new ave- nue for exploring possible adjustment of molecular packing in aggregates. The obtained results further demonstrate the importance of molecular packing in aggregated state, and show the concept of MUSIC [65-70].

Received 28 January 2021; accepted 3 March 2021; published online 20 May 2021

1 Uoyama H, Goushi K, Shizu K, et al. Highly efficient organic lightemitting diodes from delayed fluorescence. Nature, 2012, 492: 234238

2 Ding H, Li J, Xie G, et al. An AIEgen-based 3D covalent organic framework for white light-emitting diodes. Nat Commun, 2018, 9: 5234-5240

$3 \mathrm{Gu}$ PY, Zhao Y, He JH, et al. Synthesis, physical properties, and light-emitting diode performance of phenazine-based derivatives with three, five, and nine fused six-membered rings. J Org Chem, 2015, 80: 3030-3035

4 Gu PY, Wang Z, Zhang Q. Azaacenes as active elements for sensing and bio applications. J Mater Chem B, 2016, 4: 7060-7074

5 Xie C, Zhen X, Miao Q, et al. Self-assembled semiconducting polymer nanoparticles for ultrasensitive near-infrared afterglow imaging of metastatic tumors. Adv Mater, 2018, 30: 1801331

6 Zhu Z, Tian D, Gao P, et al. Cell-penetrating peptides transport noncovalently linked thermally activated delayed fluorescence nanoparticles for time-resolved luminescence imaging. J Am Chem Soc, 2018, 140: 17484-17491

7 Yang J, Chi Z, Zhu W, et al. Aggregation-induced emission: A coming-of-age ceremony at the age of eighteen. Sci China Chem, 2019, 62: 1090-1098

8 Yang J, Li Z. Visual imaging of plasma membrane: new application for aggregation induced emission (AIE) probe. Chin J Org Chem, 2019, 39: 3304-3305

9 Jiang K, Zhang L, Lu J, et al. Triple-mode emission of carbon dots: Applications for advanced anti-counterfeiting. Angew Chem Int Ed, 2016, 55: 7231-7235

10 Ji J, Hu D, Yuan J, et al. An adaptable cryptosystem enabled by synergies of luminogens with aggregation-induced-emission character. Adv Mater, 2020, 32: 2004616

11 Fang MM, Yang J, Li Z. Recent advances in purely organic room temperature phosphorescence polymer. Chin J Polym Sci, 2019, 37: 383-393

12 Yang J, Fang M, Li Z. Stimulus-responsive room temperature phosphorescence in purely organic luminogens. InfoMat, 2020, 2: 791-806

13 Hu, Y. B; Lam, J. W. Y; Hu YB, Lam JWY, Tang BZ. Recent progress in AIE-active polymers. Chin J Polym Sci, 2019, 37: 289301

14 Liu LJ, Liu W, Ji G, et al. NIR emission nanoparticles based on FRET composed of AIE luminogens and NIR dyes for two-photon fluorescence imaging. Chin J Polym Sci, 2019, 37: 401-408

15 Chen S, Yin H, Wu JJ, et al. Organic halogen-bonded co-crystals for optoelectronic applications. Sci China Mater, 2020, 63: 16131630

$16 \mathrm{He} \mathrm{J,} \mathrm{Xu} \mathrm{J,} \mathrm{Yin} \mathrm{J,} \mathrm{et} \mathrm{al.} \mathrm{Recent} \mathrm{advances} \mathrm{in} \mathrm{luminescent} \mathrm{metal-}$ organic frameworks for chemical sensors. Sci China Mater, 2019, 62: $1655-1678$

17 Yang J, Gao H, Wang Y, et al. The odd-even effect of alkyl chain in organic room temperature phosphorescence luminogens and the 
corresponding in vivo imaging. Mater Chem Front, 2019, 3: 13911397

18 Wang Y, Yang J, Gong Y, et al. Host-guest materials with room temperature phosphorescence: Tunable emission color and thermal printing patterns. SmartMat, 2020, 1: e1006

19 Bian L, Ma H, Ye W, et al. Color-tunable ultralong organic phosphorescence materials for visual UV-light detection. Sci China Chem, 2020, 63: 1443-1448

20 Wang D, Wang X, Xu C, et al. A novel metal-free amorphous room-temperature phosphorescent polymer without conjugation. Sci China Chem, 2019, 62: 430-433

21 Li Q, Li Z. Molecular packing: Another key point for the performance of organic and polymeric optoelectronic materials. Acc Chem Res, 2020, 53: 962-973

22 Yang J, Zhen X, Wang B, et al. The influence of the molecular packing on the room temperature phosphorescence of purely organic luminogens. Nat Commun, 2018, 9: 840-849

23 Lei Y, Zhou Y, Qian L, et al. Polymorphism and mechanochromism of $n$-alkylated 1,4-dihydropyridine derivatives containing different electron-withdrawing end groups. J Mater Chem C, 2017, 5: 5183-5192

24 Wang C, Yu Y, Chai Z, et al. Recyclable mechanoluminescent luminogen: different polymorphs, different self-assembly effects of the thiophene moiety and recovered molecular packing via simple thermal-treatment. Mater Chem Front, 2019, 3: 32-38

25 Zhang L, Zhao WL, Li M, et al. Recent progress on room-temperature phosphorescent materials of organic small molecules. Acta Chim Sin, 2020, 78: 1030-1040

26 Lu B, Liu S, Yan D. Recent advances in photofunctional polymorphs of molecular materials. Chin Chem Lett, 2019, 30: 19081922

27 Liu X, Jia Y, Jiang $\mathrm{H}$, et al. Two polymorphs of triphenylaminesubstituted benzo $[d]$ imidazole: mechanoluminescence with different colors and mechanofluorochromism with emission shifts in opposite direction. Acta Chim Sin, 2019, 77: 1194-1202

28 Dong Y, Xu B, Zhang J, et al. Piezochromic luminescence based on the molecular aggregation of 9,10-bis((E)-2-(pyrid-2-yl)vinyl)anthracene. Angew Chem Int Ed, 2012, 51: 10782-10785

29 Yang J, Ren Z, Xie Z, et al. AIEgen with fluorescence-phosphorescence dual mechanoluminescence at room temperature. Angew Chem Int Ed, 2017, 56: 880-884

30 Wang J, Chai Z, Wang J, et al. Mechanoluminescence or roomtemperature phosphorescence: molecular packing-dependent emission response. Angew Chem Int Ed, 2019, 58: 17297-17302

31 Zhang Z, Wu YS, Tang KC, et al. Excited-state conformational/ electronic responses of saddle-shaped $N, N^{\prime}$-disubstituteddihydrodibenzo $[a, c]$ phenazines: Wide-tuning emission from red to deep blue and white light combination. J Am Chem Soc, 2015, 137: 8509-8520

32 dos Santos PL, Etherington MK, Monkman AP. Chemical and conformational control of the energy gaps involved in the thermally activated delayed fluorescence mechanism. J Mater Chem C, 2018, 6: 4842-4853

33 Zhang Z, Chen CL, Chen YA, et al. Tuning the conformation and color of conjugated polyheterocyclic skeletons by installing orthomethyl groups. Angew Chem Int Ed, 2018, 57: 9880-9884

34 Wu H, Chi W, Baryshnikov G, et al. Crystal multi-conformational control through deformable carbon-sulfur bond for singlet-triplet emissive tuning. Angew Chem Int Ed, 2019, 58: 4328-4333

35 Wang $\mathrm{K}$, Zhang $\mathrm{H}$, Chen S, et al. Organic polymorphs: One- compound-based crystals with molecular-conformation- and packing-dependent luminescent properties. Adv Mater, 2014, 26 6168-6173

36 Mallia AR, Sethy R, Bhat V, et al. Crystallization induced enhanced emission in conformational polymorphs of a rotationally flexible molecule. J Mater Chem C, 2016, 4: 2931-2935

37 Shao B, Jin R, Li A, et al. Luminescent switching and structural transition through multiple external stimuli based on organic molecular polymorphs. J Mater Chem C, 2019, 7: 3263-3268

38 Zheng K, Ni F, Chen Z, et al. Polymorph-dependent thermally activated delayed fluorescence emitters: Understanding TADF from a perspective of aggregation state. Angew Chem Int Ed, 2020, 59: 9972-9976

39 Hosoya S. Molecular shapes of thianthrene and related heterocyclic compounds. Acta Cryst, 1963, 16: 310-312

40 Jones RN. The ultraviolet absorption spectra of anthracene derivatives.. Chem Rev, 1947, 41: 353-371

41 Ward JS, Nobuyasu RS, Fox MA, et al. Impact of methoxy substituents on thermally activated delayed fluorescence and roomtemperature phosphorescence in all-organic donor-acceptor systems. J Org Chem, 2019, 84: 3801-3816

42 Ward JS, Nobuyasu RS, Fox MA, et al. Bond rotations and heteroatom effects in donor-acceptor-donor molecules: Implications for thermally activated delayed fluorescence and room temperature phosphorescence. J Org Chem, 2018, 83: 14431-14442

43 Okazaki M, Takeda Y, Data P, et al. Thermally activated delayed fluorescent phenothiazine-dibenzo[ $a, j]$ phenazine-phenothiazine triads exhibiting tricolor-changing mechanochromic luminescence. Chem Sci, 2017, 8: 2677-2686

44 Chen C, Huang R, Batsanov AS, et al. Intramolecular charge transfer controls switching between room temperature phosphorescence and thermally activated delayed fluorescence. Angew Chem Int Ed, 2018, 57: 16407-16411

45 Tian Y, Yang X, Gong Y, et al. The initial attempt to reveal the emission processes of both mechanoluminescence and room temperature phosphorescence with the aid of circular dichroism in solid state. Sci China Chem, 2021, 64: 445-451

46 Etherington MK, Franchello F, Gibson J, et al. Regio- and conformational isomerization critical to design of efficient thermallyactivated delayed fluorescence emitters. Nat Commun, 2017, 8: 14987-14998

47 Kukhta NA, Huang R, Batsanov AS, et al. Achieving conformational control in room-temperature phosphorescence and thermally activated delayed fluorescence emitters by functionalization of the central core. J Phys Chem C, 2019, 123: 26536-26546

48 Li W, Huang Q, Mao Z, et al. Selective expression of chromophores in a single molecule: Soft organic crystals exhibiting fullcolour tunability and dynamic triplet-exciton behaviours. Angew Chem Int Ed, 2020, 59: 3739-3745

49 Zhan L, Chen Z, Gong S, et al. A simple organic molecule realizing simultaneous TADF, RTP, AIE, and mechanoluminescence: Understanding the mechanism behind the multifunctional emitter. Angew Chem Int Ed, 2019, 58: 17651-17655

50 He Z, Cai X, Wang Z, et al. Sky-blue thermally activated delayed fluorescence material employing a diphenylethyne acceptor for organic light-emitting diodes. J Mater Chem C, 2018, 6: 36-42

51 Chen Y, Chen DG, Chen YA, et al. Mono-heteroatom substitution for harnessing excited-state structural planarization of dihydrodibenzo[a,c]phenazines. Chem Eur J, 2019, 25: 16755-16764

52 Yamamoto K, Higashibayashi S. Synthesis of three-dimensional 
butterfly slit-cyclobisazaanthracenes and hydrazinobisanthenes through one-step cyclodimerization and their properties. Chem Eur J, 2016, 22: 663-671

53 Jena S, Dhanalakshmi P, Bano G, et al. Delayed fluorescence, room temperature phosphorescence, and mechanofluorochromic naphthalimides: Differential imaging of normoxia and hypoxia live cancer cells. J Phys Chem B, 2020, 124: 5393-5406

54 Yu YJ, Hu Y, Yang SY, et al. Near-infrared electroluminescence beyond $800 \mathrm{~nm}$ with high efficiency and radiance from anthracene cored emitters. Angew Chem Int Ed, 2020, 59: 21578-21584

55 Xue J, Liang Q, Wang R, et al. Highly efficient thermally activated delayed fluorescence via $j$-aggregates with strong intermolecular charge transfer. Adv Mater, 2019, 31: 1808242

56 He Z, Gao H, Zhang S, et al. Achieving persistent, efficient, and robust room-temperature phosphorescence from pure organics for versatile applications. Adv Mater, 2019, 31: 1807222

57 Zhang T, Gao H, Lv A, et al. Hydrogen bonding boosted the persistent room temperature phosphorescence of pure organic compounds for multiple applications. J Mater Chem C, 2019, 7: 9095-9101

58 Kitamoto Y, Namikawa T, Ikemizu D, et al. Light blue and green thermally activated delayed fluorescence from $10 \mathrm{H}$-phenoxaborinderivatives and their application to organic light-emitting diodes. J Mater Chem C, 2015, 3: 9122-9130

59 Wen Y, Liu H, Zhang S, et al. One-dimensional $\pi-\pi$ stacking induces highly efficient pure organic room-temperature phosphorescence and ternary-emission single-molecule white light. J Mater Chem C, 2019, 7: 12502-12508

60 Wen Y, Liu H, Zhang S, et al. Achieving highly efficient pure organic single-molecule white-light emitter: The coenhanced fluorescence and phosphorescence dual emission by tailoring alkoxy substituents. Adv Opt Mater, 2020, 8: 1901995

61 Chen X, Xu C, Wang T, et al. Versatile room-temperature-phosphorescent materials prepared from $N$-substituted naphthalimides: Emission enhancement and chemical conjugation. Angew Chem Int Ed, 2016, 55: 9872-9876

62 Li XN, Yang M, Chen XL, et al. Synergistic intra- and intermolecular noncovalent interactions for ultralong organic phosphorescence. Small, 2019, 15: 1903270

$63 \mathrm{Gu} \mathrm{L}$, Shi H, Gu M, et al. Dynamic ultralong organic phosphorescence by photoactivation. Angew Chem Int Ed, 2018, 57: 84258431

64 Yang Z, Chi Z, Mao Z, et al. Recent advances in mechano-responsive luminescence of tetraphenylethylene derivatives with aggregation-induced emission properties. Mater Chem Front, 2018, 2: 861-890

65 Li Q, Li Z. The strong light-emission materials in the aggregated state: What happens from a single molecule to the collective group. Adv Sci, 2017, 4: 1600484

66 Liu F, Liao Q, Wang J, et al. Intermolecular electronic coupling of 9-methyl-9H-dibenzo $[a, c]$ carbazole for strong emission in aggregated state by substituent effect. Sci China Chem, 2020, 63: $1435-1442$

67 Wang Y, Yang J, Tian Y, et al. Persistent organic room temperature phosphorescence: What is the role of molecular dimers? Chem Sci, 2020, 11: 833-838

68 Li Q, Li Z. Miracles of molecular uniting. Sci China Mater, 2020, 63: $177-184$

69 Li Q, Tang Y, Hu W, et al. Fluorescence of nonaromatic organic systems and room temperature phosphorescence of organic lu- minogens: The intrinsic principle and recent progress. Small, 2018, 14: 1801560

70 Yang J, Fang M, Li Z. Organic luminescent materials: The concentration on aggregates from aggregation-induced emission. Aggregate, 2020, 1: 6-18

Acknowledgements This work was supported by the National Natural Science Foundation of China (21875130), the Starting Foundation of Tianjin University and the Project of "100 Talents Program" of Shanxi Province.

Author contributions Wang J, Shi H and Li Z designed the whole work; Li S synthesized all compounds, grew and measured the crystals; Li S characterized the photo-physical properties with the help from Li X and Che W; Li S and Li A performed the data analysis; Xie Y performed the theoretical calculations; Li S wrote the paper with support from Wang J, Shi H and Li Z. All authors contributed to the general discussion.

Conflict of interest The authors declare no conflict of interest.

Supplementary information Supporting data are available in the online version of the paper.

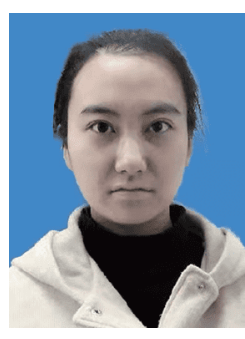

Shuhui Li received her BSc degree from Shanxi University in 2018. Now she is a Master student at the School of Chemistry and Chemical Engineering, Shanxi University. Her research interests focus on novel luminescent materials with stimuli-responsive fluorescence, room-temperature phosphorescence, and thermally activated delayed fluorescence properties.

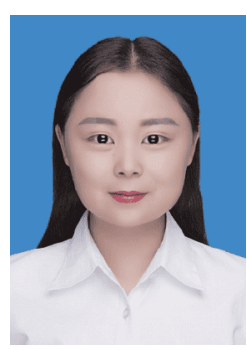

Jinfeng Wang received her BSc degree from Hubei University in 2014 and her PhD degree from Wuhan University in 2019. She has been working at Tianjin University since 2019. Her research interests are in dye-sensitized solar cells, mechanoluminescence and room-temperature phosphorescence.

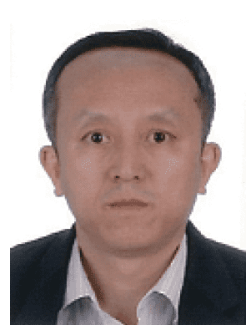

Heping Shi received his BSc degree from Taiyuan Normal University in 1991 and his $\mathrm{PhD}$ degree from Shanxi University in 2004. He has been working at Shanxi University since 1997. $\mathrm{He}$ was a visiting scholar at the Hong Kong University of Science and Technology from 2014 to 2015 and at the University of Melbourne from 2016 to 2017. His research interests are in aggregation-induced emission materials and thermally activated delayed fluorescence materials. 


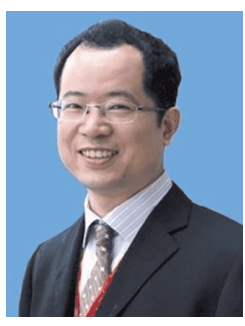

Zhen Li received his $\mathrm{BSc}$ and $\mathrm{PhD}$ degrees from Wuhan University in 1997 and 2002, respectively. He has been a full Professor at Wuhan University since 2006 and Chair Professor at Tianjin University since 2018. His research interests are in the development of organic molecules and polymers with new structures and functions for organic electronics and photonics.
不同分子构象与堆积决定力致变色与室温磷光性 能

李姝慧 ${ }^{1,2}$, 谢育俊, 李爱森 ${ }^{2}$, 李晓宁 ${ }^{2}$, 车伟龙 ${ }^{2}$, 王金风 $2^{2}$, 施和平 ${ }^{1^{*}}$, 李振 ${ }^{2,3,4^{*}}$

摘要 本文设计并合成了DBTDO-DMAC, 以及两个对比分子 DBTDO-DPA和DBTDO-Cz, 证明了分子堆积形式对发光性能的 影响. 其中, DBTDO-DMAC具有两种不同的晶型: 晶体 $G$ 表现出 明显的力致变色 $(\mathrm{MC})$ 现象, 研磨前后的苂光由绿色变为黄色, 光谱 红移 $35 \mathrm{~nm}$; 晶体 $\mathrm{Y}$ 表现出明显的黄色室温磷光 (RTP)现象. 为进一 步探究这种差异的内在机理, 结合单晶结构、粉末XRD和理论计 算等对其进行了详细分析, 结果表明分子不同的发光行为与分子 构象和堆积方式密切相关. 这种调节聚集态分子排列的方式, 为其 他MC和/或RTP发光材料的设计提供了指导, 成为进一步优化调节 有机、高分子功能材料性能的又一重要手段, 再次表明MUSIC概 念的重要性. 